\title{
Compliance to Continuous Positive Airway Pressure therapy in patients with obstructive sleep apnea - long-term assessment
}

Josefina Pascua ${ }^{1,2 *}$

Magali Blanco ${ }^{1,2}$

Glenda Ernst ${ }^{1,3}$

Alejandro Salvado

Eduardo Enrique Borsini ${ }^{1,2}$

${ }^{1}$ Hospital Británico de Buenos Aires, Sleep Unit - Buenos Aires - Ciudad Autónoma de Buenos AIres - Argentina. ${ }^{2}$ Hospital Británico de Buenos Aires, Center for Respiratory Medicine Buenos Aires - Ciudad Autónoma de Buenos AIres - Argentina.

${ }^{3}$ Hospital Británico de Buenos Aires, Teaching and Research Department Buenos Aires - Ciudad Autónoma de Buenos AIres - Argentina.
*Corresponding author: Josefina Pascua

E-mail: josefinapascuar@gmail.com / josepas15@hotmail.com

Received: September 2, 2020;

Accepted: March 1, 2021

DOI: 10.5935/1984-0063.20200118

\begin{abstract}
Introduction: To assess CPAP acquirement, compliance, and dropout rates among OSA patients three years after the prescription. Material and Methods: We assessed CPAP acquirement (Acq), compliance (Comp), and dropout (Dout) through a telephone survey. We interviewed 156 patients; ESS: 9.9 $\pm 5.7, \mathrm{AHI}>15 \mathrm{ev} /$ hour in $96.4 \% .92$ patients had accessed CPAP therapy $(58.9 \%)$ and $67(72.8 \%)$ were still using it. Dropout was reported by $25(27.2 \%)$. The Comp group was older $(p<0.01)$, had more men $(p<0.001)$, higher ESS scores $(p<0.03)$ and a higher level of specialist follow-up ( $\mathrm{p}<0.001)$. Multivariate analysis adjusted showed; follow-up by experts (OR: 4.39; $\mathrm{p}<0.05)$ and ESS $>10$ (OR: 1.25; $\mathrm{p}<0.05)$ increased CPAP compliance. Conclusion: There is a high number of patients without CPAP therapy acquirement. Long-term compliance was found in $3 / 4$ of the study population in symptomatic patients followed up by specialists. Finally, $43 \%$ had effective treatment. Keywords: Obstructive Sleep Apnea; CPAP Therapy; Compliance; Dropout.
\end{abstract}




\section{INTRODUCTION}

The prevalence of obstructive sleep apnea (OSA) ranges between $9 \%$ and $38 \%$ in the general population ${ }^{1,2}$ and it is close to $28 \%$ in Latin America ${ }^{3}$. Such data prove the need for practical strategies for almost one billion people worldwide ${ }^{4}$.

In our country, epidemiological data are based on estimates. According to the Guidelines of the Argentine Association of Respiratory Medicine ${ }^{5}$, there are more than 5 million OSA patients among the Argentine adult population. One third of them suffer from moderate-to-severe OSA and, therefore, would be candidates to continuous positive airway pressure (CPAP) therapy.

Therapy efficacy is conditioned by the correct diagnosis and treatment prescription. In the case of CPAP therapy, compliance rests on the adequacy of the device and factors like; insurance coverage, follow-up and patient's tolerance. In this way, compliance to CPAP therapy has been associated with several factors, such as perceived severity and symptomatology ${ }^{3}$.

Argentine Diagnosis and Treatment Guidelines include coverage recommendations about the diagnostic procedures for all suspected OSA patients, as well as CPAP treatment for patients with a confirmed diagnosis ${ }^{6}$.

However, since OSA is a chronic disease, compliance also depends on financial and social factors, such as socioeconomic status, economic and financial barriers to therapy?

Data published in our country reveal that barriers to CPAP therapy are related to lack of consensus in CPAP indication or treatment priorities among treating physicians and lack of health insurance coverage or financial resources ${ }^{8,9}$.

According to Latin American reports, one-third of CPAP therapy candidates never start treatmen $t^{10}$. A deeper understanding of the local problems faced by each organizational system could contribute to improve CPAP acquirement and prevent dropouts that raise risks to unacceptable levels. Thus, we decided to interview OSA patients 3 years after their indication of CPAP therapy.

\section{OBJECTIVES}

To assess CPAP acquirement, compliance, and dropout rates among OSA patients with CPAP therapy indication for three years after the prescription.

\section{MATERIAL AND METHODS}

\section{Study population}

Prospective study performed in a sample of consecutive patients with diagnosis of OSA who underwent a CPAP titration study at the Respiratory Medicine Unit of Hospital Británico, in Buenos Aires, in 2016.

The study protocol was approved by the Ethics Committee and the Institutional Review Board in accordance with the ethical principles of the declaration of Helsinki as amended (protocol: CRIHB $\neq 985$ ).

\section{Inclusion criteria}

Patients over the age of 18-years-old;

Patients with diagnosis of OSA established through polysomnography (PSG) or respiratory polygraphy (RP);
Patients with an indication of CPAP therapy according to guidelines who underwent a CPAP titration study in 2016 (at least 36 months before the telephone survey).

\section{Exclusion criteria}

Psychiatric disorders or impairments that interfere with CPAP therapy;

Refusal to take part in the survey.

\section{Clinical data}

Data were obtained from a systematic collection database belonging to the sleep unit of a University Center. We analyzed clinical data using Epworth Sleepiness Scale (ESS) scores, baseline weight and body mass index (BMI) in $\mathrm{kg} / \mathrm{m}^{2}$, severity according to baseline AHI, and CPAP titration efficacy reported by the titration study.

Treatment type and characteristics (type of device, heated humidifier, masks, and prescribed pressure) were obtained in the telephone interview and sleep unit medical records.

\section{Definitions}

Acquirement to CPAP (Acq): patients who had obtained a CPAP device either on their own or through their health insurance provider.

Dropout (Dout): a $\geq 30$-day interruption of CPAP therapy before the administration of the survey.

Compliance (Comp) group: patients using CPAP at the time of the survey.

\section{Telephone survey}

The telephone survey was conducted by 3 interviewers in April 2019. An introductory explanatory text was read out to candidates who offered to take part in the survey voluntarily and anonymously. Patients gave their express oral consent to participate.

The standardized survey seeked information on CPAP acquirement and dropout by 2 questions: "Have you accessed CPAP therapy?" (acquirement) and "Are you still using CPAP therapy?" (compliance).

- Other data gathered included the following:

- Anthropometric data;

- Indication of treating physician(s);

- Perceived disease severity;

- Symptoms and evolution during treatment;

- Intolerance to the device;

- Reported compliance rate (hours/night and days/ week);

- Characteristics of follow-up;

- Potential dropout factors;

- Coverage type and percentage;

- Administrative difficulties.

\section{Statistical analysis}

We used descriptive statistics to study the population and dropout and compliance variables. Qualitative variables were presented as absolute values and percentages. Quantitative variables with normal distribution were presented as mean values 
and standard deviation and quantitative variables without normal distribution as median values and percentiles (25-75\%). Differences were compared using Fisher's exact or $\chi^{2}$ test for qualitative variables and Mann-Whitney or student's t-test for quantitative variables.

We performed a bivariate analysis to include variables in a logistic regression model. After obtaining statistically significant predictive variables, we conducted a multivariate analysis for compliance-dropout predictors: age, sex, perception of symptoms at the beginning of therapy, and type of follow-up. Statistical analysis was conducted using GraphPad Prism-6 ${ }^{\mathbf{T M}}$ and Med Calc 12.7 software with the support of the teaching and research department.

\section{RESULTS}

Four patients refused to take part in the study. Finally, we interviewed 156 patients. Figure 1 shows patient selection. The mean time from diagnosis was 39.4 months. 101 were men (64.7\%), BMI: $31.6 \pm 9.6\left(\mathrm{~kg} / \mathrm{m}^{2}\right)$, baseline ESS: $9.9 \pm 5.7$ points, baseline AHI: $33.2 \pm 19.0 \mathrm{ev} /$ hour and an obesity proportion of $80 \%$. OSA was diagnosed by RP in $74.8 \%$ of cases and $96.4 \%$ were considered moderate-to-severe patients (AHI>15ev/h) (Table 1).

Treatment modality in compliant patients included fixed pressure CPAP (98.5\%), heat humidifier (10.4\%), nasal masks $(67.2 \%)$, oronasal masks $(28.3 \%)$, and pillows $(4.5 \%)$. The mean treatment pressure was $8.4 \pm 1.7 \mathrm{~cm}$ of $\mathrm{H}_{2} \mathrm{O}$ (Table 2$)$.

Ninety-two $(58.9 \%)$ patients acquired CPAP device and $67(72.8 \%)$ of which maintained CPAP therapy and still using it at the time of the survey. The dropout rate was 25 patients $(27.2 \%)$ with significant differences between sexes $36.1 \%$ of women and $21.4 \%$ of men) $p<0.04$.

Mean adherence in compliance group was $6.4 \pm 1.4$ hours/night. There were statistically significant differences between Comp and Dropout groups. The Comp group was older $(p<0.01)$, had more men $(p<0.001)$, higher ESS scores $(p<0.03)$, and a higher level of specialist follow-up $(p<0.001)$ (Table 3$)$.

Sex, however, did not show useful discriminatory power as a predictor of dropout: odds ratio (OR) 1.95 (95\% CI: 0.745.0), $p 0.21$ and AUC-ROC: 0.6. Reported dropout causes ( $\mathrm{n}=25$ cases) were treatment intolerance $(16.6 \%)$, perceived clinical improvement $(55.5 \%)$, and others $(27.9 \%)$.

In the case of patients without acquirement to CPAP therapy ( $\mathrm{n}=64)$, the main barriers were; lack of perception of disease relevance $(21.8 \%)$, no medical indication $(7.8 \%)$, disagreement in CPAP therapy recommendations (3.1\%), improvement without treatment $(10.9 \%)$, and difficulty in obtaining medical insurance coverage (14\%) (Figure 1). Many CPAP devices were delivered with partial coverage by health insurance companies. Table 3 shows relationship between kind of therapy and mask with dropout.

More than half of the patients without acquirement to CPAP therapy stated that they had no other available treatment alternative. In fact, CPAP therapy was the only option offered to $80 \%$ of compliance group.

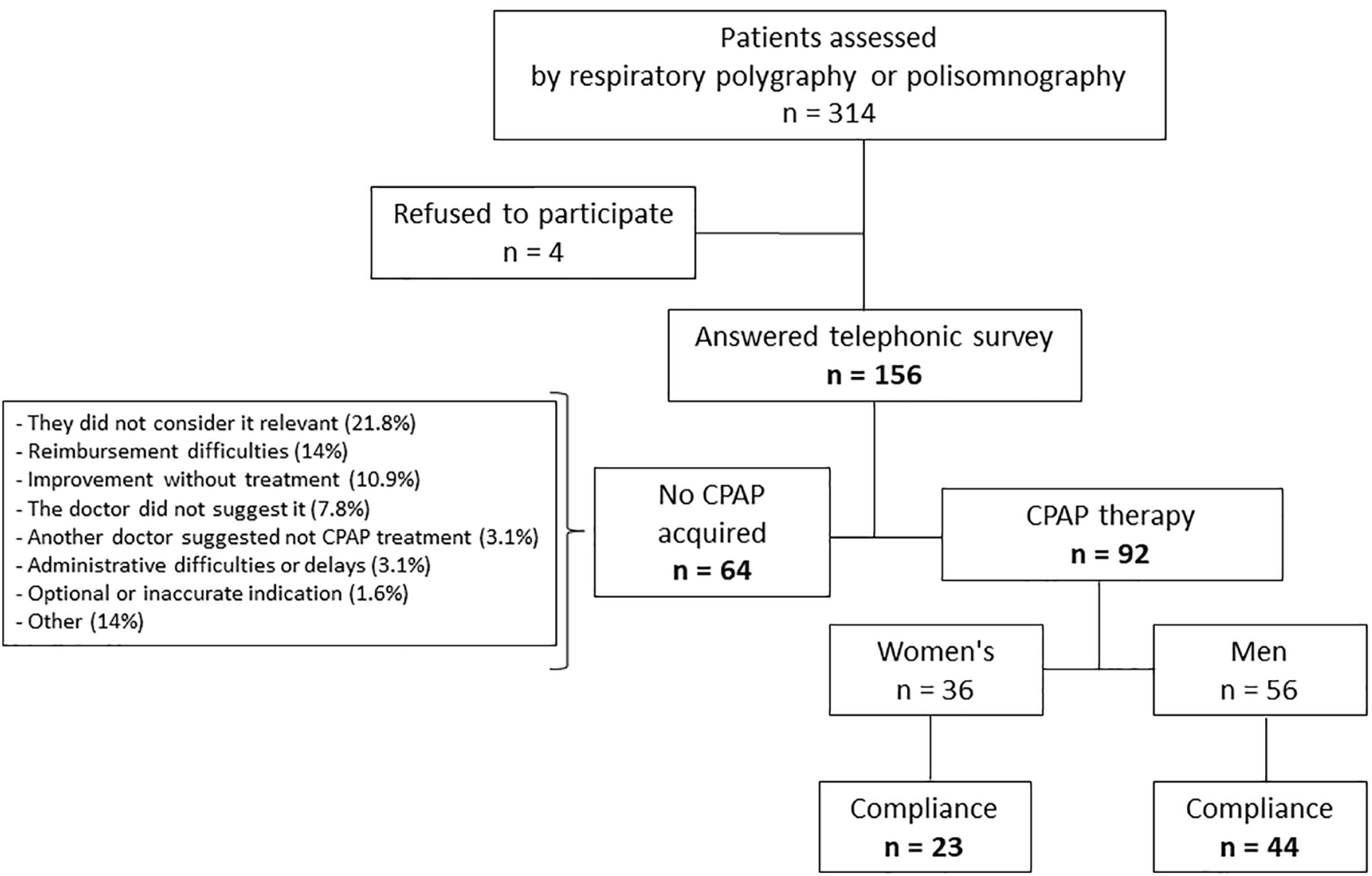

Figure 1. Patient selection flowchart. 
Table 1. Characteristics of study population $(\mathrm{n}=156)$.

\begin{tabular}{lc}
\hline Age (years) & $64.6 \pm 10.8$ \\
\hline BMI $\left(\mathrm{kg} / \mathrm{m}^{2}\right)$ & $31.6 \pm 9.6$ \\
Obesity $\left(\mathrm{BMI}>30 \mathrm{~kg} / \mathrm{m}^{2}\right)$ & $125(80.6 \%)$ \\
Sex $($ men $)$ & $101(64.7 \%)$ \\
Diagnosed using respiratory polygraphy $(\mathrm{n}=\%)$ & $116(74.8)$ \\
CPAP compliance during titration $(\mathrm{min})$ & $362 \pm 96.3$ \\
Baseline ESS score (points) & $9.9 \pm 5.7$ \\
Baseline AHI (ev/h) & $33.2 \pm 19.0$ \\
AHI $>5-<15 \mathrm{ev} / \mathrm{h}(\%)$ & 3.6 \\
AHI $>15-<30 \mathrm{ev} / \mathrm{h}(\%)$ & 37.0 \\
\hline
\end{tabular}

$\overline{\text { Notes: } \mathrm{BMI}=\text { Body mass index; } \mathrm{AHI}=\text { Apnea-hypopnea index; CPAP: Continuous }}$ positive airway pressure.

Table 2. Treatment characteristics in both groups that used CPAP therapy.

\begin{tabular}{lcc}
\hline & Dropout $(n=25)$ & Compliance $(n=67)$ \\
\hline Fixed pressure CPAP therapy (\%) & 100 & 98.5 \\
Auto-adjusting CPAP machine (\%) & $*$ & 1.5 \\
Heat-humidifier (\%) & $*$ & 10.4 \\
Prescribed pressure (cm H2O) & $9.5 \pm 0.71$ & $8.4 \pm 1.7$ \\
Time from the beginning of & 24 & $39.4 \pm 28.7$ \\
therapy (months) & $*$ & $6.4 \pm 1.4$ \\
Reported hours of use & $*$ & $6.5 \pm 1.2$ \\
Reported use (days per week) & $*$ & 4.5 \\
Nasal pillows (\%) & 80 & 67.2 \\
Nasal mask (\%) & 20 & 28.3 \\
Oronasal mask (\%) & $*$ & $17.1 \pm 11.5$ \\
Age of mask (months) & $3(12)$ & $16(23.9)$ \\
Attendance to CPAP education & & \\
program (n; \%) & &
\end{tabular}

Table 3. Characteristics of Dropout group $(n=25)$ as compared to Compliant group $(\mathrm{n}=67)$.

\begin{tabular}{l|cccc}
\hline Variable & $\begin{array}{c}\text { A + B } \\
\text { CPAP } \\
\text { acquired } \\
(\mathbf{n = 9 2 )}\end{array}$ & $\begin{array}{c}\text { A } \\
\text { Dropout } \\
(\mathbf{n = 5})\end{array}$ & $\begin{array}{c}\text { B } \\
\text { Compliance } \\
(\mathbf{n = 6 7 )}\end{array}$ & $\mathbf{p}^{*}$ \\
\hline $\begin{array}{l}\text { Age (years) } \\
\text { BMI (kg/m2) }\end{array}$ & $\begin{array}{c}64.9 \pm 10.5 \\
31.6 \pm 9.5\end{array}$ & $58.3 \pm 10.3$ & $66.3 \pm 10.6$ & 0.01 \\
$\begin{array}{l}\text { Male sex } \\
\text { (n=\%) }\end{array}$ & $56(60.8 \%)$ & $12(48 \%)$ & $44(65.6 \%)$ & 0.001 \\
$\begin{array}{l}\text { Initial CPAP } \\
\text { compliance } \\
\text { (min/night) }\end{array}$ & $356 \pm 96.3$ & $329 \pm 144$ & $336 \pm 102$ & 0.27 \\
$\begin{array}{l}\text { Baseline ESS } \\
\text { score (points) }\end{array}$ & $9.9 \pm 5.4$ & $9.10 \pm 6.8$ & $12.5 \pm 5.4$ & 0.03 \\
$\begin{array}{l}\text { Baseline AHI } \\
\text { (ev/hour) }\end{array}$ & $27.4 \pm 20.2$ & $24.4 \pm 19.0$ & $28.6 \pm 20.6$ & 0.36 \\
$\begin{array}{l}\text { Specialist } \\
\text { follow-up } \\
\text { (n=\%) }\end{array}$ & & $3(12 \%)$ & $46(68.6 \%)$ & 0.001 \\
\hline
\end{tabular}

Notes: $\mathrm{CPAP}=$ Continuous positive airway pressure BMI $=$ Body mass index; $\mathrm{AHI}$ $=$ Apnea-hypopnea index; ${ }^{*}$ Statistical significance: $\mathrm{p}$-value $>0.05$.

The multivariate analysis adjusted for sex and age showed that; follow-up by experts in respiratory medicine (OR: $4.39 ; p<0.05)$ and ESS $>10$ (OR: 1.25, 95\% IC: 1.04-1.52, $p<0.05)$ significantly increased patients' probability of CPAP compliance (Table 4).

\section{DISCUSSION}

This analysis, conducted in OSA patients diagnosed according to standard guidelines who underwent a CPAP
Table 4. Adjusted multivariate analysis and predictive model.

\begin{tabular}{lccc}
\hline & OR & $\mathbf{9 5 \%} \mathbf{C I}$ & $\mathrm{p}^{*}$ \\
\hline Specialist follow-up & 4.39 & $1.5-12.75$ & $<\mathbf{0 . 0 5 *}$ \\
ESS (>10) & 1.25 & $1.04-1.52$ & $<\mathbf{0 . 0 5 *}$ \\
Age (>50 year) & 0.46 & $0.13-1.6$ & 0.3 \\
Male sex & 0.74 & $0.1-5.0$ & 0.7 \\
\hline
\end{tabular}

Notes: $\mathrm{OR}=$ Odds ratio $; 95 \% \mathrm{CI}=$ Confidence interval.

titration study, evidenced difficulties in acquirement and a dropout rate of $27 \%$ at the third year.

Only $43 \%$ of patients received effective treatment 39 months after CPAP indication, which revealed deficiencies in therapy initiation and follow-up processes. In our assessment, compliance according to sex differed from that reported in previous studies on chronic diseases ${ }^{11}$. Men with more symptoms (defined by a high ESS score) showed higher compliance to treatment.

In 2018, Nogueira et al. ${ }^{10}$ studied a sample of 213 patients with moderate-to-severe OSA $(\mathrm{IAH}>15 \mathrm{ev} / \mathrm{h})$ and an indication of CPAP therapy in the City of Buenos Aires. They found that $71 \%$ had accessed CPAP therapy but $15.5 \%$ dropped out before month 18 . Though all patients had some kind of health insurance coverage, differences in access depended on coverage percentage: $59.2 \%$ received complete coverage and $49.2 \%$ partial coverage $(p<0.001)$. Likewise, we found that one fourth of acquirement barriers related to coverage-related problems.

In the City of Mexico, Torres-Bouscoulet et al. (2007) ${ }^{12}$ described that $34.8 \%$ of patients did not access CPAP therapy after its indication. In a study conducted in Chile, approximately two thirds of OSA patients with an indication of CPAP therapy were still on treatment after a 12 -month follow-up ${ }^{13}$. It is worth highlighting that $25 \%$ of Chilean patients who stopped using CPAP alleged financial reasons ${ }^{13}$. In spite of having different health systems in terms of organization and financing, other under developed countries in our region have reported similar difficulties in CPAP acquirement ${ }^{10-13}$.

Argentina has a universal healthcare system and, therefore, at least in theory, all individuals should have access to health care. In addition, there are several jurisdictions and fragmented institutions which results in multiple decisionmaking centers around the country ${ }^{14}$, and the consequent delays and difficulties in treatment delivery.

In our data, reported monetary difficulties represent a modest percentage $(14 \%)$ of cases. It is possible that others factors related with health organization could be responsible to did not get CPAP therapy, as administrative delays and unclear regulations.

Other potentially determining factors of acquirement and compliance are the methods used to deliver CPAP devices and follow-up patients. Local researchers have suggested that administrative delays and lack of communication among stakeholders undermine access and compliance to treatment ${ }^{15,16}$. In this sense, there is evidence of an actual problem in the delivery of CPAP devices to patients ${ }^{17}$. A 5-center study conducted in the City of Buenos Aires evaluated 195 adult OSA patients with an indication of CPAP therapy. These devices were delivered by 22 different companies. Besides, significant 
differences in machine quality, technical support, and patient training and delay in administrative procedures. The actual delivery delay of CPAP devices was of $42.1 \pm 60.7$ days.

OSA treatment efficacy does not depend solely on direct coverage. Rather, it calls for a strategic alliance among patients, patients' families, healthcare centers, CPAP machine suppliers, and the community as a whole ${ }^{15}$.

In our setting, we have a specific education program for patients ${ }^{8}$, however, this strategy was neither mandatory nor binding, so attendance to our "CPAP school" was poor. Geographical and travel difficulties in large urban centers that limit the monitoring and education of patients could be complemented with telematics strategies or telemedicine.

The need to lower costs and increase treatment efficacy in these patients has promoted the development of remote surveillance to monitoring treatment using different tools ${ }^{18,19}$. Remote surveillance with data transmission via Bluetooth, by phone, or using the internet is perceived as an alternative to improve compliance in the medium and long-term ${ }^{20}$, although the optimal organizational model and stakeholder roles in this model remain unclear ${ }^{19}$.

To the best of our knowledge, this is the first study conducted in our country that reports a long-term ( $>3$ years) $72.8 \%$ compliance to CPAP. This information is of great value. We used a simple tool (i.e., telephone calls), as described by similar studies ${ }^{15}$, and found that, in line with findings from other under developed countries, more than half of the patients are not using CPAP therapy ${ }^{11-17}$.

A recent publication by the Argentine Society of Respiratory Medicine has pointed out the importance of treatment coverage and urged all stakeholders to discuss possible solutions addressing 3 levels: management, logistics, and administration and clinical aspect ${ }^{10}$.

Another drawback is the lack of alternatives other than CPAP therapy, as described by Nogueira et al. $(2018)^{10}$. Stakeholders should discuss the possibility of having multiple treatments options and focus on educating the medical community and implementing organized healthcare policies ${ }^{10}$.

\section{CONCLUSION}

According to our results, a large proportion of patients with clinically relevant OSA have no effective CPAP therapy despite confirmed diagnosis and correct titration. Long-term compliance is observed in three-fourths of the study population. Higher compliance is reported by more symptomatic patients and those followed up by specialists.

\section{FUNDING SOURCE}

No funds were received in support of this study.

\section{DISCLOSURE}

The authors of this study do not have any kind of relationship or interest in any organization or for-profit entity (eg, fees, scholarship, entities in charge of arranging lectures, membership, employment, shares, etc.), expert testimony, license or patent agreement, nor any non-financial interest (eg, personal or professional relationships, membership, knowledge, and beliefs) related to the topic or the materials discussed herein.

\section{REFERENCES}

1. Young T, Palta M, Dempsey J, Skatrud J, Weber S, Badr S. The occurrence of sleep-disordered breathing among middle-aged adults. N Engl J Med. 1993 Apr;328(17):1230-6.

2. Durán J, Esnaola S, Ramón R, Iztueta A. Obstructive sleep apnea-hypopnea and related clinical features in a population-based sample of subjects aged 30 to 70 years. Am J Respir Crit Care Med. 2001 Mar;163(3 Pt 1):685-9.

3. Senaratna CV, Perret JL, Lodge CJ, Lowe AJ, Campbell BE, Matheson MC, et al. Prevalence of obstructive sleep apnea in the general population: a systematic review. Sleep Med Rev. 2017 Aug;34:70-81.

4. Benjafield AV, Ayas NT, Eastwood PR, Heinzer R, Ip MSM, Morrell MJ et al. Estimation of the global prevalence and burden of obstructive sleep apnoea: a literature-based analysis. Lancet Respir Med. 2019 Aug;7(8):687-98.

5. Nogueira F, Nigro C, Cambursano H, Borsini E, Silio J, Avila J. Practica guidelines for the diagnosis and treatment of obstructive sleep apnea syndrome. Medicina (B Aires). 2013;73(4):349-62.

6. Nogueira F, Borsini E, Cambursano H, Smurra M, Dibur E, Franceschini $\mathrm{C}$, et al. Guías prácticas de diagnóstico y tratamiento del síndrome de apneas e hipopneas obstructivas del sueño: actualización 2019. Rev Am Med Respir. 2019 Mar;19(1):59-90.

7. Mcardle N, Devereux G, Heidarnejad H, Engleman H, Mackay T, Douglas N. Long-term use of CPAP therapy for sleep apnea/hypopnea syndrome. Am J Respir Crit Care Med. 1999 Apr;159(4 Pt 1):1108-14.

8. Decima T, Maldonado L, Bosio M, Salvado A, Campos J, Quadrelli S, et al. Cumplimiento y abandono de CPAP en pacientes con síndrome de apneas del sueño. Rev Am Med Respir. 2013 Dec;13(4):197-206.

9. Nogueira F, Luca M, Simonelli G, Vera D, Vera S, Rey R. ¿Qué pasa con los pacientes luego de que se les diagnostica Apneas del Sueño?. Rev Am Med Respir. 2007;7(2):41-7.

10. Nogueira JF, Simonelli G, Giovini V, Angelloti MF, Borsini E, Ernst G et al Access to CPAP treatment in patients with moderate to severe sleep apnea in a Latin American City. Sleep Sci. 2018 May/Jun;11(3):174-82.

11. Sandoval D. Influencia de factores psicosociales en la adherencia al tratamiento farmacológico antihipertensivo: Resultados de una cohorte del Programa de Salud Cardiovascular de la Región Metropolitana, Chile. Rev Méd Chile. 2014 Oct;142(10):1245-52.

12. Torre-Bouscoulet L, López-Escárcega E, Castorena-Maldonado A, Vázquez-García JC, Meza-Vargas MS, Pérez-Padilla R. Continuous positive airway pressure used by adults with obstructive sleep apneas after prescription in a public referral hospital in Mexico city. Arch Bronconeumol. 2007;43:16-21.

13. Santin J, Jorquera A J, Jordán J, Bajut F, Masalán AP, Mesa LT, et al Uso de CPAP nasal en el largo plazo en síndrome de apnea-hipopnea del sueño. Rev Méd Chile. 2007;135(7):855-61.

14. Arce HE. Organización y financiamiento del sistema de salud en la argentina. Medicina (B Aires). 2012;72:414-8.

15. Borsini E, Décima T. ¿Cómo debemos organizar el seguimiento de los pacientes con síndrome de apneas-hipopneas durante el sueño?. Rev Am Med Respir. 2014;2:187-9.

16. Nogueira JF, Borsini E, Nigro C. Estrategias para mejorar la adaptación al tratamiento con CPAP en pacientes con SAHOS. Rev Am Med Respir. 2016 Dec;16(4):365-77.

17. Nogueira JF, Giovini V, Borsini E, Grosso A, Ernst G, Nigro C, et al Evaluación de la calidad de servicio prestado a pacientes con apneas del sueño por parte de diferentes proveedores de CPAP. Abstract $43^{\circ}$ Congreso Argentino de Medicina Respiratoria. Rev Am Med Resp. 2015;(Supl 1):1-89. http://www.ramr.org/articulos/suplemento_43_ congreso/43_congreso_aamr_trabajos.pdf

18. Bouloukaki I, Giannadaki $\bar{K}$, Mermigkis C, Tzanakis N, Mauroudi $\mathrm{E}$, Moniaki $\mathrm{V}$, et al. Intensive versus standard follow-up to improve continuous positive airway pressure compliance. Eur Respir J. 2014 Nov;44(5):1262-74.

19. Bruyneel M. Telemedicine in the diagnosis and treatment of sleep apnoea. Eur Respir Rev. 2019;28:180093.

20. Agüero SL, Larrateguy L, Nogueira F, Franceschini C, Smurra M, Cambursano $\mathrm{H}$, et al. Tratamiento con presión positiva de la apnea obstructiva del sueño. Posición de la Asociación Argentina de Medicina Respiratoria. Rev Am Med Respir. 2019;4:332-48. 